\title{
Size and position are incongruous: Measurements on the Müller-Lyer figure
}

\author{
BARBARA GILLAM and DEBORAH CHAMBERS \\ Schnurmacher Institute for Vision Research \\ State University of New York, State College of Optometry, New York, New York
}

\begin{abstract}
The congruence between perception of position and perception of size was measured for MüllerLyer figures. Subjects were able to set a computer-controlled dot below each apex of the illusion figures with very slight error. Under the same stimulus conditions, large size illusions were obtained as expected. Not only does this finding rule out many explanations of the Müller-Lyer illusion, but it also shows that size cannot be derived from a representation of spatial positions. In a second experiment, using brief exposures and a staircase technique, systematic position errors were found. These did not account in either magnitude or direction for the size illusions obtained for the same figures.
\end{abstract}

It has become apparent in recent years that there are incongruities in judgments of the spatial properties of configurations eliciting illusions. The best known of these is the Morinaga paradox (Figure 1) (Morinaga \& Ikeda, 1965), in which ingoing and outgoing Müller-Lyer fins are apparently displaced laterally relative to each other, but in a direction inconsistent with the apparent horizontal distances between them. This paradox has been explained in various ways, including suggestions of changes from a horizontal to a vertical figure-ground organization as the subject goes from size judgments to position judgments (Restle, 1976) and assimilation of the corners to the overlap of the parallels (Day, Bellamy, \& Norman, 1983). However, the importance of the Morinaga paradox would seem to be in the implication that position and size can be incongruous. If supported, this implication would suggest that size is not obtained from endpoint coordinates in a coherent (e.g., Euclidian) representation of space, but is arrived at independently of position and subject to influences different from those affecting perception of position. Because of the importance of this implication, we decided to measure the congruence between perception of size and perception of position in the simplest possible manner by using computer displays of each of the two halves of the Müller-Lyer configuration and a control figure (see Figure 2). Although the idea that position and size are incongruous is implicit in many previous discussions of illusions (Day, 1977; Woodworth, 1938), it does not seem to have been tested in a direct and simple fashion. This has become easier to do with the availability of computer-controlled oscilloscope displays.

This study was supported by NIMH Grant MH 30840 to the first author. The authors wish to acknowledge computer programming by Thomas Russo and helpful discussions with Michael Cook.

The authors' mailing address is: Department of Vision Sciences, State University of New York, State College of Optometry, 100 East 24th Street, New York, NY 10010-3677.

\section{EXPERIMENT 1}

The apparent position of each vertex was measured by requiring subjects to move a computer-controlled dot, which was placed well below the figure, until it appeared directly beneath the vertex. The method and apparatus are described in more detail below. Measurements were made separately for right and left vertices for each of the MüllerLyer configurations (ingoing and outgoing fins) and the control figure (a line with no fins) shown in Figure 2. The apparent sizes of the shafts in the same three figures were obtained by having subjects match a line without fins to each of them in length. For these measurements, the comparison line was placed below the test line, but displaced laterally from it. These two kinds of measurements allowed for a comparison of the apparent sizes of the Müller-Lyer and control shafts with the apparent positions

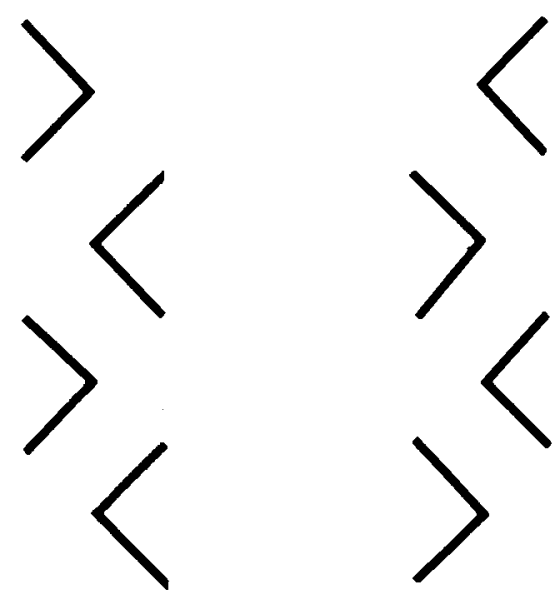

Figure 1. Moringga's paradox: The vertices of the ingoing and outgoing Müller-Lyer fins appear displaced in a direction that is inconsistent with the perceived extent. 

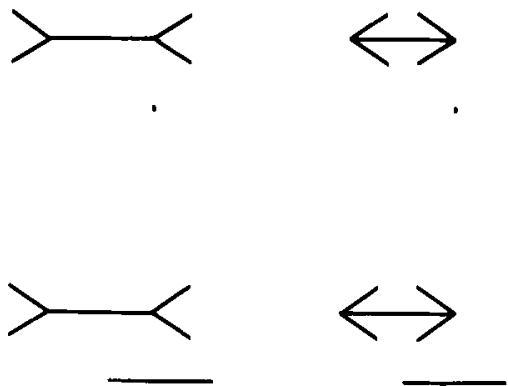

Figure 2. A scale drawing of the stimuli presented in Experiments 1 and 2.

of the shaft endpoints measured under the same conditions. If the visual representation of the length of a line stands in a congruous relationship to the positions of its endpoints and other points in the visual field, then indices of position should also show an illusory displacement. The dot-alignment task provides such an index. If the apparent position of the endpoints has changed, then the positions at which the dots appear vertically aligned with the endpoints should also change. The dot-alignment task adds very little to the basic Müller-Lyer configuration, and it should therefore allow assessment of positional effects without thereby causing a major reorganization of the figure.

A secondary interest of this experiment was to investigate the kind of process that causes the Müller-Lyer illusion. Any theory that postulates a distortion in the cortical representation of the endpoints of the line under the influence of the fins should predict a displacement of the dots in the alignment task. For example, Burns and Pritchard (1971) state "An erroneous assessment of the real distance between the tips of two remote angles results if an observer's assessment partly depends upon the cortical locus of the intersection of the lines that form an angle" (p. 614). Ginsberg's (1971) theory that the visual system attenuates the high spatial frequency components of the image also predicts such a displacement. Eye-movement theories or "efferent readiness" theories (Festinger, White, \& Allyn, 1968; Judd, 1905; Virsu, 1971; and more tentatively, Restle \& Decker, 1977), that attribute the illusion to a misperception of the position of the apices because of an overshoot or undershoot in programmed eye position, should also predict a deviation in the dotalignment task. (It is clear that actual eye movements are not responsible for illusions.) The tendency to fixate an angle at the center of gravity of the component lines has been demonstrated independently of tasks involving length judgments (Richards \& Kaufman, 1969). Even one version of the constancy scaling theory (Gillam, 1978) attributes the Müller-Lyer and other illusions to an "orthogonalization" of angles, in which lines forming acute angles are shortened and lines forming obtuse angles are lengthened (see Figure 3). A constancy scaling process of this type must also predict a congruence between apparent line length and the apparent position of line endpoints for the Müller-Lyer configurations. However, it is not necessary to assume that constancy scaling works by means of an orthogonalization process (Gillam, 1980). Most recently, Stuart, Day, and Dickinson (1984) pointed out a number of difficulties in attributing the Müller-Lyer illusion to processes within size channels and proposed that it was derived from position information.

\section{Method}

Ten subjects were recruited from the SUNY College of Optometry. All of the subjects had 20/20, or corrected to 20/20, visual acuity. The subjects were paid $\$ 5$ for their participation in the experiment.

The three test figures (see Figure 2) were generated by a PDP11/40 computer and were presented on a Hewlett-Packard 1310A oscilloscope. The control line and the horizontal shafts of the two Müller-Lyer figures were each $75 \mathrm{~mm}$ in length. Each segment of the Müller-Lyer fins was $32 \mathrm{~mm}$ in length and joined the shaft in an angle of $40^{\circ}$. All of the lines forming the figure were $1.2 \mathrm{~mm}$ in width. The figures were centered on the oscilloscope screen.

The subjects were seated in a dark room $140 \mathrm{~cm}$ from the oscilloscope screen. Their heads were positioned in a chinrest that put their eyes approximately level with the display. Fixation was not required.

In Condition 1, a dot (actually a small line $1 \times 5 \mathrm{~mm}$ ), adjustable in lateral position, was located $60 \mathrm{~mm}$ below the figure. The subjects were asked to align the dot with the vertex of the MüllerLyer or the endpoint of the control figure. They made the adjustments by using a push-pull linear potentiometer calibrated with respect to position or length. To prevent the subjects from forming a consistent relationship between a specific movement of the potentiometer and the position of the dot on the screen, the potentiometer was set to the center of its range before each trial, but the dot position this represented (the starting position of the dot) was programmed to vary randomly within a $40-\mathrm{mm}$ range $(20 \mathrm{~mm}$ to the left or right of the objective point of alignment). The dot was adjustable throughout this $40-\mathrm{mm}$ range.

In Condition 2, a horizontal line, adjustable in length, was positioned $60 \mathrm{~mm}$ below the figure. The subjects were asked to adjust the length of this line to match the length of the horizontal line in each of the two Müller-Lyer figures and the control figure. The left endpoint of the adjustable line was aligned with the center of the figure, and extended to the right, varying in lateral length from 50 to $100 \mathrm{~mm}$. The length of the line was adjustable to any length within

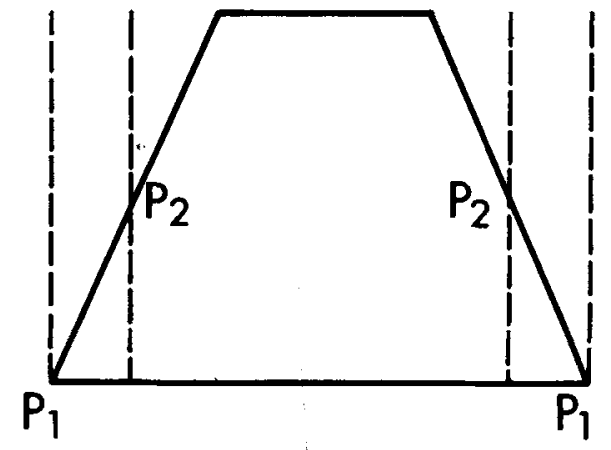

Figure 3. Perceiving the trapezoid to be more like a rectangle implies pivot points around which the obliques are rotated. If the pivot points were placed at $P_{2}$, there would be equal and opposite size illusions for the acute and obtuse angle-bounded lines. As the pivot point moves toward $P_{1}$ at the acute-angle end, the illusion at that end will decrease and the illusion at the obtuse-angle end will increase, leading to the prediction of a negative correlation between the two forms of the illusion. 
this 50 -mm range. As in Condition 1 , the adjustments were made with a linear potentiometer.

All of the 10 subjects participated in both conditions of the experiment. Condition 1, the dot-alignment task, consisted of 30 trials. Each subject made five settings for both the left and right vertices of each Müller-Lyer figure and for the two endpoints of the control figure. Condition 2, the size task, consisted of 15 trials. Each subject made five length adjustments for each of the three figures. The order of presentation of Conditions 1 and 2 was counterbalanced between subjects.

In both conditions of the experiment, the subjects terminated a trial by pressing a switch. This signaled the computer to store the setting and prompt the experimenter for the next trial. The data were recorded as deviations of the subjects' settings from the point of objective alignment (Condition 1) or objective equality (Condition 2).

\section{Results}

The results are given in Table 1. They show large classical Müller-Lyer size illusions (see Table 1, extent measures). The outgoing-fin figure showed a larger illusion than the ingoing-fin figure, a finding in line with previous data. However, errors in the perception of vertex position were very small (see Table 1 , position measures), accounting for about $16 \%$ of the size effect. This was shown by calculating "derived extents" for each subject, using the two mean vertex settings as endpoints. Table 1 shows the derived extents for each condition expressed as deviations from the true extent of the line. The direct measures of perceived extent, which are also given as deviations from true extent, are given in the same table for comparison purposes. A positive extent or derived extent is longer than the true extent, whereas a negative extent or derived extent is shorter than the true extent.

With reference to the principal purpose of the experiment, our data indicate that size and position responses were markedly incongruous and presumably based on independent responses to the visual input. Size judgments were subject to contextual influences in a way that position judgments were not. Our results refute theories of the Müller-Lyer illusion based on a misperception or blurring of the vertex position of the angles of the MüllerLyer figures. This may occur to a small degree, accounting for the $16 \%$ effect we obtained, but if this were the only distortion, the Müller-Lyer illusion would be unknown. The size illusion is attributable mainly to other causes. Coren (1970) found a $40 \%$ reduction in the Müller-Lyer illusion when he used dot figures instead of line figures. He attributes this $40 \%$ of the illusion magnitude to retinal and optical components. In another study, using a "cyclopean" procedure, Coren and Porac (1984) assessed the contribution of structural factors to the illusion at $47 \%$. The essential idea here was to introduce noise consisting of randomly oriented arrowheads which were segregated in depth from the Müller-Lyer figure. Under monocular conditions, this segregation would disappear and the global figure would be masked, leaving only local "structural" factors operating. According to Coren and Porac, these include optical blur, neural interactions, lateral inhibition at the retinal and cortical levels, and Fourier transforms of the retinal intensity patterns. In that
Table 1

Measures of Position and Extent Using the Adjustment Method (Experiment 1)

\begin{tabular}{|c|c|c|c|c|}
\hline \multirow[b]{2}{*}{ Subject } & \multicolumn{2}{|c|}{ Position Measures } & \multicolumn{2}{|c|}{ Extent Measures } \\
\hline & Left Apex & Right Apex & Derived Extent & Extent \\
\hline \multicolumn{5}{|c|}{ Control Figure } \\
\hline 1 & $0.92 \mathrm{R}$ & $0.97 \mathrm{~L}$ & -1.89 & 1.57 \\
\hline 2 & $0.46 \mathrm{R}$ & $0.05 \mathrm{~L}$ & -0.51 & 2.93 \\
\hline 3 & $0.55 \mathrm{~L}$ & $0.79 \mathrm{R}$ & 1.34 & 2.93 \\
\hline 4 & $0.72 \mathrm{R}$ & $0.37 \mathrm{R}$ & -0.35 & -0.61 \\
\hline 5 & $2.99 \mathrm{R}$ & $1.04 \mathrm{R}$ & -1.95 & 1.95 \\
\hline 6 & $1.46 \mathrm{R}$ & $2.44 \mathrm{R}$ & 0.98 & 1.57 \\
\hline 7 & $1.77 \mathrm{R}$ & $0.86 R$ & -0.91 & -0.01 \\
\hline 8 & $0.37 \mathrm{R}$ & $0.68 \mathrm{R}$ & 0.31 & -1.19 \\
\hline 9 & $0.61 \mathrm{~L}$ & $1.34 \mathrm{R}$ & 1.95 & 2.20 \\
\hline 10 & $1.40 \mathrm{R}$ & $2.69 \mathrm{R}$ & 1.29 & 0.49 \\
\hline Mean & $0.89 \mathrm{R}$ & $0.92 R$ & 0.03 & 1.18 \\
\hline SD & 1.08 & 1.08 & 1.37 & 1.44 \\
\hline \multicolumn{5}{|c|}{ Outgoing-Fin Figure } \\
\hline 1 & $0.31 \mathrm{~L}$ & $1.77 \mathrm{R}$ & 2.08 & 15.02 \\
\hline 2 & $1.97 \mathrm{~L}$ & $0.73 \mathrm{R}$ & 2.70 & 15.63 \\
\hline 3 & $0.92 \mathrm{~L}$ & $2.50 \mathrm{R}$ & 3.42 & 18.80 \\
\hline 4 & $0.25 \mathrm{~L}$ & $1.34 \mathrm{R}$ & 1.59 & 15.02 \\
\hline 5 & $2.56 \mathrm{R}$ & $4.60 \mathrm{R}$ & 2.04 & 17.09 \\
\hline 6 & $0.24 \mathrm{R}$ & $3.11 \mathrm{R}$ & 2.87 & 23.20 \\
\hline 7 & $1.16 \mathrm{~L}$ & $2.20 \mathrm{R}$ & 3.36 & 19.48 \\
\hline 8 & $0.43 R$ & $0.92 R$ & 0.49 & 9.09 \\
\hline 9 & $0.89 \mathrm{~L}$ & $2.93 R$ & 3.82 & 5.74 \\
\hline 10 & $0.12 \mathrm{R}$ & $4.03 R$ & 3.91 & 14.59 \\
\hline Mean & $0.22 \mathrm{~L}$ & $2.41 \mathrm{R}$ & 2.63 & 15.36 \\
\hline SD & 1.22 & 1.28 & 1.08 & 5.01 \\
\hline \multicolumn{5}{|c|}{ Ingoing-Fin Figure } \\
\hline 1 & $1.10 \mathrm{R}$ & $0.49 \mathrm{R}$ & -0.61 & -9.66 \\
\hline 2 & $1.10 \mathrm{R}$ & $1.37 \mathrm{~L}$ & -2.47 & -6.84 \\
\hline 3 & $0.31 \mathrm{~L}$ & $0.61 R$ & 0.92 & -9.65 \\
\hline 4 & $0.61 \mathrm{R}$ & $0.12 \mathrm{R}$ & -0.49 & -11.58 \\
\hline 5 & $3.24 \mathrm{R}$ & $2.39 \mathrm{R}$ & -0.85 & -9.66 \\
\hline 6 & $0.73 \mathrm{R}$ & $0.73 \mathrm{R}$ & 0.00 & -9.74 \\
\hline 7 & $2.81 \mathrm{R}$ & $0.37 \mathrm{~L}$ & -3.18 & -5.42 \\
\hline 8 & $0.31 \mathrm{~L}$ & $2.29 \mathrm{~L}$ & -1.98 & -6.11 \\
\hline 9 & $0.79 \mathrm{R}$ & $0.12 \mathrm{R}$ & -0.67 & -4.27 \\
\hline 10 & $2.69 \mathrm{R}$ & $0.80 \mathrm{R}$ & -1.89 & -7.81 \\
\hline Mean & $1.24 \mathrm{R}$ & $0.12 \mathrm{R}$ & -1.12 & -8.07 \\
\hline SD & 1.26 & 1.28 & 1.24 & 2.35 \\
\hline
\end{tabular}

Note: Each entry in the table is the mean of five adjustments. $L$ and $R$ refer to errors to the left or right in the point of subjective alignment. Positive and negative signs are explained in the text.

most of these factors would work by shifting apex position, our data are not in agreement with an estimate as high as $47 \%$. At least part of the attenuation Coren found with the dot figures may have been due to the weakness of the dot figure as compared with a line figure, in eliciting size-scaling processes. In the cyclopean experiment, the global figure may not have been completely masked under monocular conditions, as Coren and Porac intended, since it is demarcated with red dots.

Our data are not incompatible with theories that attribute the illusion to processes within size "channels" (e.g., Brigell \& Uhlarik, 1979) or with theories that propose constancy reasons for the perceptual enlargement of lines forming obtuse angles and the perceptual diminution of lines forming acute angles (Gillam, 1980). 
One criticism that could be leveled at Experiment 1 is that the magnitude of illusion may be determined by where the subject is looking, and this may vary from one task to the other. For example, subjects might be looking in the center of the figure for the size judgments and at the appropriate vertex for the vertical alignments. It is possible that no illusion, or a smaller illusion, occurs when the subject is looking at a vertex, either because it is viewed foveally or because a less holistic response to the figure occurs under these circumstances. To check this possible explanation of our results, we carried out another experiment in which we controlled for fixation, with size and position judgments being made under the same fixation conditions.

\section{EXPERIMENT 2}

In Experiment 2, a fixation point was added prior to each exposure of the test figures used in Experiment 1. The same fixation points were used for position and size judgments. To prevent the subjects from moving their eyes away from the fixation point when making their judgments, the test stimulus was presented too briefly $(150 \mathrm{msec})$ to allow for refixation. Because of the necessity for a brief presentation, the method of adjustment used in Experiment 1 was replaced with a double random staircase method. As in Experiment 1, the figures were created by a PDP-11/40 computer and were displayed on a Hewlett-Packard 11310 oscilloscope screen.

\section{Method}

Six subjects were recruited from the State University of New York College of Optometry. All of the subjects had 20/20, or corrected to $20 / 20$, visual acuity. The subjects were paid $\$ 5$ per session for their participation in the experiment. The experiment was conducted in two sessions which were separated by no more than 7 days.

For position measures, subjects were asked on each trial if a dot, located $60 \mathrm{~mm}$ below the figure, was to the left or right of the vertex of a Müller-Lyer figure or the endpoint of the control figure. Prior to exposure of the figures and dot, the subjects were instructed to direct their gaze to a fixation point located in one of three positions, and to keep their eyes "locked" on the point throughout the trial. The fixation point was located either in the center of the figure, $37.5 \mathrm{~mm}$ from each vertex, or to the left or right periphery of the figure, $37.5 \mathrm{~mm}$ from the closest vertex (see Figure 4). In no condition was the subject fixating the vertex. This should remove any increase in accuracy for the position judgments relative to the size judgments that might result from fixation behavior. The fixation point preceded the presentation of the figure by $1,000 \mathrm{msec}$ and remained on during the brief presentation of the test figure (150 msec).

All of the subjects participated in the trials requiring fixation in the center of the figure. Three of the six subjects also participated in the trials requiring fixation on the left peripheral point, and the three other subjects also participated in the trials requiring fixation on the right peripheral point. Each subject was measured under 12 different conditions, each composed of one of the three test figures (fins in, fins out, or control), a fixation point (central or peripheral), and one of two vertices (left or right). The order of presentation of the 12 conditions was randomized for each subject. For each condition, the position of the dot was varied between trials in a double random staircase design. One staircase started $20 \mathrm{~mm}$ to the left of the point of objective alignment, and the other staircase started

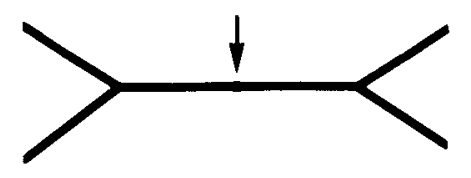

-

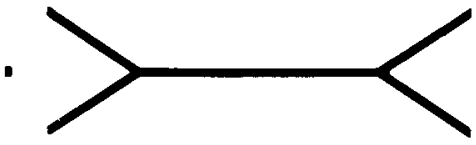

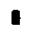

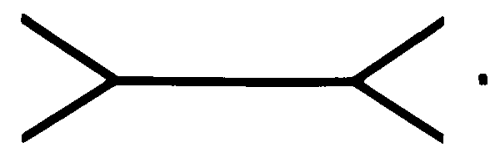

-

Figure 4. A scale drawing of the three fixation conditions(center, left, and right) for the outgoing Müller-Lyer fins, presented in Experiment 2. The arrow indicates the position of the center fixation point.

$20 \mathrm{~mm}$ to the right of the point of objective alignment. The position of the dot advanced in 2-mm steps. Both staircases were continued until seven reversals were obtained for each.

Length measures followed the same procedure as the alignment measures, except that the subjects were asked on each trial whether a line, located $60 \mathrm{~mm}$ below the test figure and displaced laterally, was longer or shorter than the horizontal line in the test figure. The subjects were instructed not to include the fins of the Müller-Lyer figures in their judgments. There was one length measurement for each figure, making six conditions in all (three figures and two fixation conditions-central and peripheral). On each trial, the length of the comparison line was varied by the use of a double random staircase procedure. One staircase started with the line $20 \mathrm{~mm}$ shorter than required for objective equality, whereas the other staircase started with the line $20 \mathrm{~mm}$ longer than required for objective equality. The length of the line advanced in $2-\mathrm{mm}$ steps. As before, each staircase was presented until seven reversals were obtained.

In both types of measures used in Experiment 2, the subjects made their responses verbally to the experimenter. The experimenter typed the responses into the computer terminal. The computer stored the responses and then selected the next trial randomly.

For all subjects, alignment and size measurements were obtained on separate days. The order of presentation was counterbalanced between subjects.

To view the displays, the subjects were seated in a dark room $140 \mathrm{~cm}$ from the oscilloscope screen. Their heads were positioned in a chinrest, with their eyes approximately level with the display.

\section{Results}

The results of all three fixation conditions for the alignment task are shown in Tables 2-5. The data can be sum- 
Table 2

Point of Subjective Equality for Position Using the Staircase Method (Experiment 2) Central Fixation

\begin{tabular}{|c|c|c|c|c|}
\hline \multirow[b]{2}{*}{ Subject } & \multicolumn{2}{|c|}{ Left Apex } & \multicolumn{2}{|c|}{ Right Apex } \\
\hline & Mean & SD & Mean & $\mathrm{SD}$ \\
\hline \multicolumn{5}{|c|}{ Control Figure } \\
\hline 1 & $2.58 \mathrm{~L}$ & 2.40 & $6.92 \mathrm{R}$ & 1.94 \\
\hline 2 & $1.25 \mathrm{R}$ & 1.23 & $6.93 R$ & 1.80 \\
\hline 3 & $1.78 \mathrm{~L}$ & 1.84 & $0.82 R$ & 1.93 \\
\hline 4 & $2.96 \mathrm{~L}$ & 1.80 & 0.0 & 1.73 \\
\hline 5 & $3.93 \mathrm{R}$ & 1.80 & $2.96 \mathrm{R}$ & 1.80 \\
\hline 6 & $0.49 \mathrm{R}$ & 1.33 & $2.96 \mathrm{R}$ & 0.73 \\
\hline & $0.28 \mathrm{~L}$ & 2.66 & $3.43 \mathrm{R}$ & 2.95 \\
\hline \multicolumn{5}{|c|}{ Ingoing-Fin Figure } \\
\hline 1 & $1.44 \mathrm{~L}$ & 1.80 & $5.25 \mathrm{R}$ & 2.53 \\
\hline 2 & $1.44 \mathrm{~L}$ & 1.67 & $0.05 \mathrm{~L}$ & 1.33 \\
\hline 3 & $1.87 \mathrm{~L}$ & 1.93 & 0.00 & 1.67 \\
\hline 4 & $2.97 \mathrm{~L}$ & 2.54 & $1.29 \mathrm{~L}$ & 2.54 \\
\hline 5 & $2.96 \mathrm{~L}$ & 2.17 & $2.72 \mathrm{R}$ & 1.93 \\
\hline 6 & $3.19 \mathrm{~L}$ & 1.20 & $3.54 \mathrm{R}$ & 1.20 \\
\hline & $2.31 \mathrm{~L}$ & 0.81 & $1.69 \mathrm{R}$ & 2.52 \\
\hline \multicolumn{5}{|c|}{ Outgoing-Fin Figure } \\
\hline 1 & $0.32 \mathrm{R}$ & 1.93 & $6.40 \mathrm{R}$ & 2.54 \\
\hline 2 & $1.94 \mathrm{R}$ & 1.93 & $4.95 \mathrm{R}$ & 2.40 \\
\hline 3 & $1.24 \mathrm{R}$ & 2.54 & $0.66 \mathrm{R}$ & 1.40 \\
\hline 4 & $0.98 \mathrm{~L}$ & 3.13 & $2.50 \mathrm{~L}$ & 1.34 \\
\hline 5 & $5.77 \mathrm{~L}$ & 1.33 & $7.20 \mathrm{R}$ & 2.53 \\
\hline \multirow[t]{3}{*}{6} & $0.84 \mathrm{~L}$ & 1.80 & $2.80 \mathrm{R}$ & 1.80 \\
\hline & $0.68 \mathrm{~L}$ & 2.74 & $3.25 \mathrm{R}$ & 3.69 \\
\hline & $12 / 18 \mathrm{~L}$ & & $15 / 18 \mathrm{R}$ & \\
\hline
\end{tabular}

marized as follows: For all three figures, subjects tended to see the vertex displaced away from the prior fixation position. (This is illustrated schematically in Figure 5.) The proportion of trials in which this result was obtained for each fixation condition (added across all figures) is given at the bottom of Tables 2, 3, and 4. For peripheral fixation, the errors tended to be small at the closer vertex and larger at the more distant vertex, regardless of which figure was present (see Tables 3 and 4). This, combined with the tendency to see the vertex as displaced from the fixation point, meant that the position errors for vertices tended to be consistent with an enlargement of the figure for both the ingoing and the outgoing fins as well as the control figure (see Figure 5). This is shown by the tendency for positive derived extents for all the figures (see Table 5). The position data thus predict a positive size illusion in all cases. This did not occur. The size judgments followed their usual pattern: an enlargement of the figure with the outgoing fins, a diminution of the figure with the ingoing fins, and little illusion for the control figure (see Table 5-extent data).

There were two cases (see Table 5) in which there was no illusion, or a very small illusion, for the outgoing-fin figure, a very unusual result for this figure. One subject (2) also showed an attenuation for the ingoing-fin figure. It appears that under brief exposure conditions, which presumably tap the characteristics of initial visual processing, some subjects under some conditions are able to dissociate shaft from fins in judging length. This did not happen for any subject in Experiment 1, where a long exposure was used. However, it is not an entirely novel finding. Reynolds (1978) showed a strong reduction in illusion for some subjects at brief exposure durations for the Ponzo and Zöllner illusions. Note that in our data the subjects with very little size illusion were just as likely to have position errors as were those with a strong size illusion.

Apparent extents of the shafts are shown in Table 5 (as deviations from the true extents) for each condition, where they can be compared in detail with the corresponding

Table 3

Point of Subjective Equality for Position Using the Staircase Method (Experiment 2) Left Fixation

\begin{tabular}{|c|c|c|c|c|}
\hline \multirow[b]{2}{*}{ Subject } & \multicolumn{2}{|c|}{ Left Apex } & \multicolumn{2}{|c|}{ Right Apex } \\
\hline & Mean & SD & Mean & SD \\
\hline \multicolumn{5}{|c|}{ Control Figure } \\
\hline 1 & $2.32 \mathrm{R}$ & 3.14 & $0.65 R$ & 1.80 \\
\hline 2 & 0.0 & 1.33 & $2.97 R$ & 2.54 \\
\hline 3 & $2.51 \mathrm{R}$ & 1.84 & $0.99 \mathrm{~L}$ & 1.93 \\
\hline \multicolumn{5}{|c|}{ Ingoing-Fin Figure } \\
\hline 1 & $6.92 \mathrm{R}$ & 3.14 & $9.43 R$ & 1.93 \\
\hline 2 & $3.02 R$ & 1.80 & $5.37 \mathrm{R}$ & 3.00 \\
\hline 3 & $1.54 \mathrm{R}$ & 1.20 & $1.44 \mathrm{R}$ & 1.93 \\
\hline \multicolumn{5}{|c|}{ Outgoing-Fin Figure } \\
\hline 1 & 4.30R & 3.14 & $12.85 \mathrm{R}$ & 3.20 \\
\hline 2 & $1.65 R$ & 1.33 & 4.48R & 2.40 \\
\hline \multirow[t]{3}{*}{3} & $2.89 \mathrm{R}$ & 1.93 & $4.46 \mathrm{R}$ & 1.33 \\
\hline & $2.79 \mathrm{R}$ & 1.95 & $4.52 \mathrm{R}$ & 4.35 \\
\hline & $9 / 9 \mathrm{R}$ & & $8 / 9 \mathrm{R}$ & \\
\hline
\end{tabular}

Table 4

Point of Subjective Equality for Position Using the Staircase Method (Experiment 2) Right Fixation

\begin{tabular}{|c|c|c|c|c|}
\hline \multirow[b]{2}{*}{ Subject } & \multicolumn{2}{|c|}{ Left Apex } & \multicolumn{2}{|c|}{ Right Apex } \\
\hline & Mean & SD & Mean & SD \\
\hline \multicolumn{5}{|c|}{ Control Figure } \\
\hline 4 & $6.49 \mathrm{~L}$ & 3.44 & $0.59 \mathrm{~L}$ & 1.80 \\
\hline 5 & $5.31 \mathrm{~L}$ & 3.60 & $2.90 \mathrm{R}$ & 1.93 \\
\hline 6 & $1.97 \mathrm{R}$ & 1.33 & $0.54 \mathrm{R}$ & 1.67 \\
\hline \multicolumn{5}{|c|}{ Ingoing-Fin Figure } \\
\hline 4 & $2.23 \mathrm{~L}$ & 3.74 & $1.97 \mathrm{~L}$ & 1.67 \\
\hline 5 & $2.01 \mathrm{~L}$ & 1.20 & $0.59 \mathrm{R}$ & 1.20 \\
\hline 6 & $2.03 \mathrm{~L}$ & 1.20 & $1.98 \mathrm{~L}$ & 1.93 \\
\hline \multicolumn{5}{|c|}{ Outgoing-Fin Figure } \\
\hline 4 & $3.95 \mathrm{~L}$ & 2.40 & $4.05 \mathrm{~L}$ & 1.94 \\
\hline 5 & $1.98 \mathrm{~L}$ & 1.33 & $1.92 \mathrm{~L}$ & 0.60 \\
\hline \multirow[t]{3}{*}{6} & $4.01 \mathrm{~L}$ & 1.80 & $0.98 \mathrm{~L}$ & 1.33 \\
\hline & $2.89 \mathrm{~L}$ & 2.43 & $0.82 \mathrm{~L}$ & 2.00 \\
\hline & $8 / 9 \mathrm{~L}$ & & $6 / 9 \mathrm{~L}$ & \\
\hline
\end{tabular}



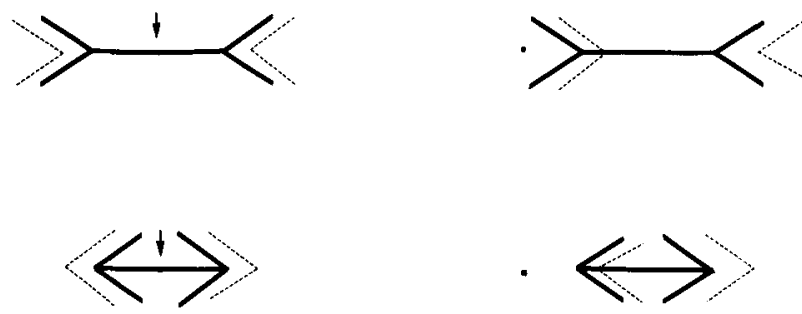

Figure 5. An illustration of the subjects' tendency to perceive the vertex of the Müller-Lyer fins as displaced away from the fixation point. The arrows indicate the position of the center fixation point.

derived extents. The important point, which is obvious from inspection of the table, is that there was little relationship between the position errors and the extent errors. In the ingoing-fin case, it is worth noting that the extents and derived extents were of opposite sign in all cases except one. The Pearson product-moment correlation coefficient between extents and derived extents for the ingoingfin figure with central fixation was +.41 and was not significant. Even in the outgoing-fin figure, where derived extents and extents tended to be of the same sign, there is poor quantitative agreement between derived extents and extents in most cases. The correlation coefficient for derived extents and extents for the outgoing-fin conditions under central fixation $(-.42)$ was not significant. The fact that extents and derived extents have the same sign for the outgoing figure appears to be a fortuitous result of the fact that the size illusion for this figure happens to be in the same direction as the position errors obtained with peripheral fixation for all three figures.

It is not clear why we obtained the pattern of position errors we did. Deviations of fixation do not explain them, since such deviations should affect the apparent position of both vertex and the point being aligned with it.

\section{DISCUSSION}

The results of Experiment 2 support the finding of Experiment 1 that the size illusion cannot be predicted from the apparent position of the apices. The difference between the two experiments was that, in Experiment 1, the apices showed little position error, but the size error was large. In Experiment 2, the apices showed considerable error, as did the size matches, but the former did not account for the latter.

It is clear from these experiments that the illusory size enhancement caused by placing fin attachments on a line is not the by-product of a change in the apparent position

Table 5

Extent Measures (Experiment 2)

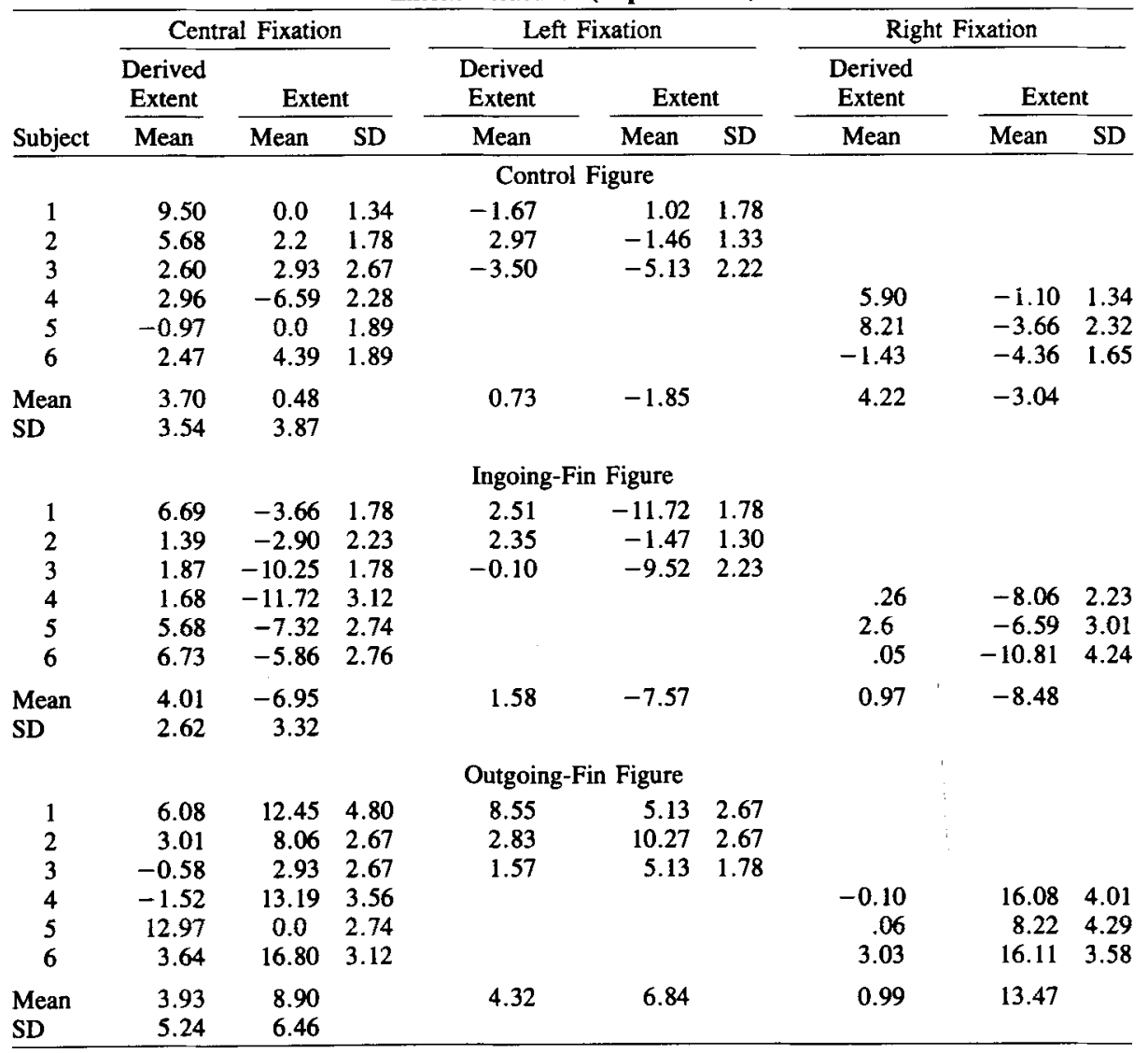


of its endpoints. It is not surprising, therefore, that it has been reported that reaching to the vertices is also rather accurate for the Müller-Lyer figure (Cook, 1979; Mack, personal communication, 1984). Eye movements also seem to be little affected by the illusion if the instructions to look at the vertex are very precise (Wong, 1981). In accounting for these data, it is not necessary to postulate a separate representation guiding action that preserves position information not available to conscious perception, since the present results show that conscious percepts of size and position are themselves incongruous.

It is of interest to note that if the position of the whole figure is being judged and not just its endpoints, there can be an impression of a directional shift resulting from asymmetric size illusions. This is the case in Figure 6, which is Holding's (1970) version of the Judd (1899) figure. The upper line appears enlarged on the left and diminished on the right, whereas the lower line, whose vertices are vertically aligned with those of the upper line, appears enlarged on the right and diminished on the left. The midpoints of the shafts in Figure 6 can be seen to be displaced in opposite directions on the shafts, reflecting the enlargements within the figure (Morgan, 1969). Despite this global impression of displacement, our present data indicate that the local vertices and midpoints would nevertheless be correctly located in space relative to undistorted parts of the visual field, showing that local position is correctly represented.

The reason that relative local position is not affected by the contextual features that produce illusions may be its importance in guiding eye movements. If two objects of different size at different distances have their ends aligned vertically, the eyes will have to make a saccade in a vertical direction to look from one to the other, despite the fact that the more distant object will look much wider. An example would be the relationships between the points a, b, c, and d in Figure 7. Hochberg (1974) pointed out the importance of preserving visual field relationships in eye-movement guidance. However, size, like shape and color, is important mainly for recognition, and it is important that its distal rather than its proximal nature be perceived. Such judgments are much more subject to context effects than are judgments of local position, and it

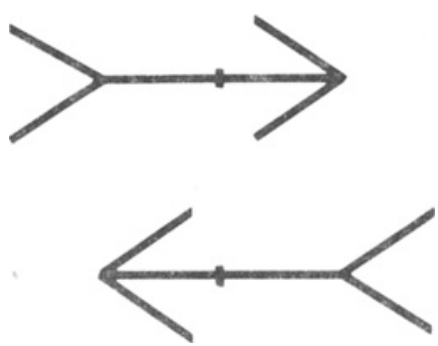

Figure 6. Each line appears asymmetric in size around its midpoint (shown by a dot), which causes a global impression that the upper figure is displaced leftwards relative to the lower figure. This effect is even greater if the page is turned 90 .

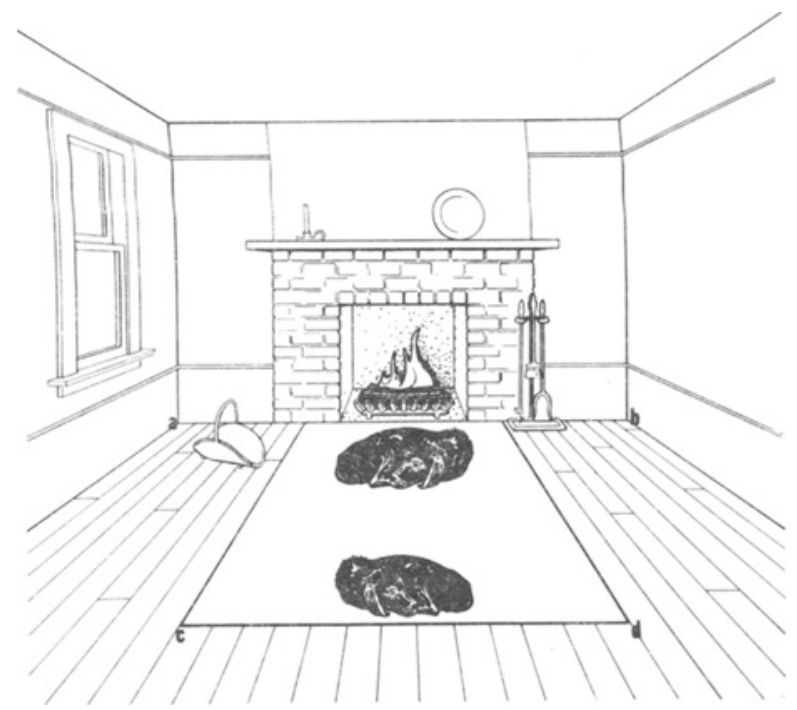

Figure 7. The length of the line A-B appears longer than C-D, despite the fact that the endpoints $A, C$ and $B, D$ are vertically aligned.

has been argued elsewhere that these context effects, when applied in the natural three-dimensional environment, in general have the function of yielding a veridical percept of the distal stimulus (Gillam, 1980; Gregory, 1963).

It would be premature to assume that the relative position of points in the visual field is always accurately perceived. It may also be subject to illusions under certain conditions. What is certain is that size and position can be shown to be perceptually incongruous under conditions in which this is unlikely to be attributable to a change in the organization of the figure and that they are subject to different influences. This makes it unlikely that they are derived from each other or read off from a common representation, and strongly suggests that they are independent responses to the available proximal information. The postulation of a single representation, such as Marr's (1982) 21/2 D sketch, from which spatial properties are derived, may be called into question.

\section{REFERENCES}

Brigell, M., \& UhlaRIK, J. (1979). The relational determination of length illusions and length aftereffects. Perception, 8, 187-197.

Burns, D., \& Pritchard, R. (1971). Geometrical illusions and the response of neurons in the cat's visual cortex to angle patterns. Journal of Physiology, 213, 599-616.

Cook, M. (1979). Visual representation. Invited address at the Annual Conference of the Experimental Psychology Society, Canberra, Australia.

COREN, S. (1970). Lateral inhibition and geometric illusions. Quarterly Journal of Experimental Psychology, 22, 274-278.

Corf, , S., \& Porac, C. (1984). Structural and cognitive components in the Müller-Lyer illusion assessed via Cyclopean presentation. Perception \& Psychophysics, 35, 313-318.

DAY, R. H. (1977). Perceptual assimilation as a basis for a class of components in geometrical illusions. In R.H. Day \& G.V. Stanley (Eds.), Studies in perception. Perth: University of Western Australia Press.

Day, R. H., Bellamy, S. \& Norman, A. (1983). On the Morinaga misalignment illusion. Joumal of Experimental Psychology: Human Perception and Performance, 9, 113-125. 
Festinger, L., White, C. W., \& Allyn, M. R. (1968). Eye movements and decrements in the Müller-Lyer illusion. Perception \& Psychophysics, 3, 376-382.

GillaM, B. (1978). A constancy-scaling theory of the Müller-Lyer illusion. In J.P. Sutcliffe (Ed.), Conceptual analysis and method in psychology, Essays in Honor of W.M. O'Neil. Sydney: Sydney University Press.

Gillam, B. (1980). Geometrical illusions. Scientific American, 242, 102-111.

GinsBurg, A. (1971). Psychological correlates of a model of the human visual system. Proceedings 1971 Naecon, 283-290.

GREGORY, R.L. (1963). Distortion of visual space as inappropriate constancy scaling. Nature, 199, 678-680.

HoCHBERG, J. (1974). Higher-order stimuli and inter-response coupling in the perception of the visual world. R. B. Macleod \& H. L. Pick (Eds.), In Perception: Essays in honor of James J. Gibson. Ithaca, NY: Cornell University Press.

Holding, D.H. (1970). A line illusion with irrelevant depth cues. American Journal of Psychology, 83, 280-282.

JudD, C. H. (1899). A study of geometrical illusions. Psychological Review, 6, 241-261.

JudD, C. H. (1905). The Müller-Lyer illusion. Psychological Review Monograph Supplement, 29, 55-82.

MARR, D. (1982). Vision. San Francisco: Freeman.

Morgan, M. J. (1969). Estimates of length in a modified Müller-Lyer figure. Joumal of Experimental Psychology, 82, 380-384.

Morinaga, S., \& IKeDA, H. (1965). Paradox of displacement in geometrical illusion and the problem of dimensions-A contribution to the study of space perception. Japanese Journal of Psychology, 36, 231-238.

Restle, F. (1976). Morinaga's paradox and figure ground organization. Perception \& Psychophysics, 20, 153-156.

Restle, F., \& DeCKER, J. (1977). Size of the Müller-Lyer illusion as a function of its dimensions: Theory and data. Perception \& Psychophysics, 21, 489-503.

Reynolds, R. I. (1978). The microgenetic development of the Ponzo and Zöllner illusions. Perception \& Psychophysics, 23, 231-236.

Richards, W., \& KaUfman, L. (1969). "Center of gravity" tendencies for fixations and flow pattern. Perception \& Psychophysics, 19, 526-544.

StUaRT, G.W., DAY, R.H., \& Dickinson, R.G. (1984). Müller-Lyer: Illusion of size or position? Quarterly Journal of Experimental Psychology, 36A, 663-672.

VIRSU, V. (1971). Tendencies to eye movement and misperception of curvature, direction and length. Perception \& Psychophysics, 9, 65-72.

WONG, E. (1981). Information used by the oculomotor system in saccadic programming and the relationship of perceptual and saccadic responses. Unpublished doctoral dissertation, The New School for Social Research, Graduate Faculty.

WoODWORTH, R. S. (1938). Experimental psychology. New York: Holt.

(Manuscript received November 15, 1984; revision accepted for publication May 15, 1985.) 